\title{
Laser interstitial thermal therapy for pediatric atypical teratoid/rhabdoid tumor: case report
}

\author{
Abdullah H. Feroze, MD,1 Margaret McGrath, MD,1 John R. Williams, MD,1 \\ Christopher C. Young, MD, PhD, ${ }^{1}$ Chibawanye I. Ene, MD, PhD, ${ }^{1}$ Robert T. Buckley, MD, ${ }^{1}$ \\ Bonnie L. Cole, MD, ${ }^{3}$ Jeffrey G. Ojemann, MD, PhD, ${ }^{1,2}$ and Jason S. Hauptman, MD, PhD ${ }^{1,2}$ \\ 'Department of Neurological Surgery, University of Washington; and Departments of ${ }^{2}$ Neurological Surgery and ${ }^{3} \mathrm{Pathology}$, \\ Seattle Children's Hospital, Seattle, Washington
}

\begin{abstract}
Herein, the authors describe the successful use of laser interstitial thermal therapy (LITT) for management of metastatic craniospinal disease for biopsy-proven atypical teratoid/rhabdoid tumor in a 16-month-old boy presenting to their care. Specifically, LITT was administered to lesions of the right insula and left caudate. The patient tolerated 2 stages of LITT to the aforementioned lesions without complication and with evidence of radiographic improvement of lesions at the 2and 6-month follow-up appointments. To the authors' knowledge, this represents the first such published report of LITT for management of atypical teratoid/rhabdoid tumor.
\end{abstract}

https://thejns.org/doi/abs/10.3171/2019.10.FOCUS19746

KEYWORDS laser interstitial thermal therapy; LITT; atypical teratoid/rhabdoid tumor; ATRT; pediatric brain tumor

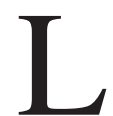
ASER interstitial thermal therapy (LITT) is a minimally invasive procedure that, when combined with MRI, has been found to be useful in treating a variety of intracranial pathologies in both the pediatric and adult population. LITT can prove particularly advantageous in the treatment of patients who are deemed high-risk surgical candidates or in the setting of pathologies located in surgical areas (i.e., eloquent cortex) that are difficult or dangerous to access or those complicated by multiple recurrences requiring repeat resection.,13

LITT involves the use of a laser system in conjunction with MRI. Briefly, lasers are a form of nonionizing radiation that produce a coherent and monoenergetic beam of light energy that can be delivered with minimal loss over relatively long distances. The effectiveness of laser treatment on a tissue can be determined by absorption and scatter. Absorption occurs when the laser energy is converted to heat after its photons hit molecules in the target tissue called chromophores. The transfer of energy to the chromophores results in the release of heat, allowing photothermal heating to take place, which directly damages adjacent cells and structures via protein denaturation. Scatter takes place when the trajectory of the photon is deviated by its interaction with particles in the tissue, resulting in an increased spatial distribution of light. ${ }^{19}$ To promote selective photothermolysis of tissue, a wavelength must be chosen in which photon scatter and absorption are optimized for tissue heating and penetration of light. Several properties of tissue such as perfusion, conductivity, specific heat, and density are also critical components of how laser may affect tissue. Laser energy is delivered from generator to tissue by use of long, highly flexible, fiberoptic cables that operate as waveguides for the light.

The goal of LITT is thermal ablation and coagulation of the target area with minimal morbidity to adjacent tissue. Target tissue destruction occurs via protein denaturation. Tissue damage is a complex function of temperature delivered and exposure time. ${ }^{8}$ LITT is guided by MRI, not only for spatial information and guidance, but also for thermal monitoring. The procedure is monitored by MR thermometry. This can evaluate the local tissue conditions for resorbing heat prior to giving a therapeutic dose by applying nondestructive warmth to the target area and observing the response. The maximum volume that can be successfully ablated is limited by the penetrability of brain tissue. Estimates of damage to the tissue can be made by using the cumulative heating estimated by MR thermometry. There is no uniform dose of thermal energy per unit

ABBREVIATIONS ATRT = atypical teratoid/rhabdoid tumor; LITT = laser interstitial thermal therapy; PNET = primitive neuroectodermal tumor; SEGA = subependymal giant cell astrocytoma.

SUBMITTED September 6, 2019. ACCEPTED October 16, 2019.

INCLUDE WHEN CITING DOI: 10.3171/2019.10.FOCUS19746. 
TABLE 1. Review of LITT in pediatric neuro-oncology (2010-2019)

\begin{tabular}{|c|c|c|c|}
\hline Authors \& Year & Pathology & Results & Complications \\
\hline Jethwa et al., 2011 & Supratentorial PNET & $\begin{array}{l}\text { Reduced lesion size, } w / \text { increase in size after } \\
\text { receiving concomitant radiation; resolution } \\
\text { of symptoms }\end{array}$ & None \\
\hline Dadey et al., 2016 & SEGA & $\begin{array}{l}\text { Followed for 4-9 mos w/ decrease in mass } \\
\text { size; resolution of symptoms }\end{array}$ & None \\
\hline $\begin{array}{l}\text { Tovar-Spinoza \& Choi, } \\
2016\end{array}$ & $\begin{array}{l}\text { Pilocytic astrocytoma }(n=6) \text {, ependy- } \\
\text { moma, SEGA, medulloblastoma, } \\
\text { ganglioglioma, choroid plexus } \\
\text { xanthogranuloma }\end{array}$ & $\begin{array}{l}\text { Reduced tumor size in all but } 1 \text { SEGA case w/ } \\
\text { recurrence; improvement in symptoms }\end{array}$ & $\begin{array}{l}\text { Hemiparesis, mutism, \& transient leg } \\
\text { weakness; no long-term complica- } \\
\text { tions }\end{array}$ \\
\hline Kuo et al., 2019 & $\begin{array}{l}\text { Ganglioglioma }(n=2) \text {, focal cortical } \\
\text { dysplasia, radiation necrosis, } \\
\text { gliosis }\end{array}$ & $\begin{array}{l}\text { Reduction in size of lesions, reduced symp- } \\
\text { toms, seizure freedom in all cases }\end{array}$ & No long-term deficits \\
\hline Lewis et al., 2015 & Focal cortical dysplasia & $\begin{array}{l}\text { Engel class I outcome achieved in } 41 \% \text {, Engel } \\
\text { class II in } 6 \% \text {, Engel class III in 18\%, \& } \\
\text { Engel class IV in } 35 \%\end{array}$ & $\begin{array}{l}\text { Inaccurate fiber placement, intra- } \\
\text { ventricular hemorrhage, aseptic } \\
\text { meningitis, ventriculostomy, posta- } \\
\text { blation edema, device malfunction }\end{array}$ \\
\hline Buckley et al., 2016 & $\begin{array}{l}\text { HH }(n=6) \text {, SEGA ( } n=3) \text {, hypo- } \\
\text { thalamic tumors ( } n=3 \text {; glioma, } \\
\text { ganglioglioma, \& pleiomorphic } \\
\text { xanthoastrocytoma) }\end{array}$ & $\begin{array}{l}\text { HH: } 67 \% \text { seizure free w/ remaining hav- } \\
\text { ing }>90 \% \text { reduction compared w/ preop } \\
\text { baseline; SEGA: clinical, radiographic } \\
\text { tumor control in } 2 \text { cases; palliative ablation } \\
\text { of hypothalamic/3rd ventricular tumors } \\
\text { resulted in partial tumor control in } 1 \text { of } 3 \\
\text { patients }\end{array}$ & $\begin{array}{l}\text { Transient hemiparesis, diplopia, \& } \\
\text { intralesional hemorrhage, hydro- } \\
\text { cephalus }\end{array}$ \\
\hline Xu et al., 2018 & $\mathrm{HH}$ & $\begin{array}{l}61 \% \text { had full disconnection of } \mathrm{HH} ; 80 \% \text { of pa- } \\
\text { tients w/ gelastic seizures \& } 56 \% \text { of patients } \\
\text { w/ nongelastic seizures were seizure free }\end{array}$ & $\begin{array}{l}\text { Immediate complications: } 39 \% \text { w/ } \\
\text { neurological deficits, including } \\
1 \text { case of hemiparesis; end of } \\
\text { follow-up: } 22 \% \text { of patients w/ } \\
\text { persistent deficits }\end{array}$ \\
\hline
\end{tabular}

$\mathrm{HH}=$ hypothalamic hamartoma.

volume of any given target tissue. Thermal delivery cutoff points are determined in real time as temperatures reach adequate thresholds through the entire mapped target, largely dependent on lesion size.,.,6

First introduced for the treatment of brain lesions in the 1990s, LITT has demonstrated utility in a wide array of pathologies with minimal side effects, providing a viable alternative to surgical extirpation, chemotherapy, and radiation. In the adult population, LITT has been used to treat gliomas, ${ }^{22}$ recurrent metastases, ${ }^{17}$ radiation necrosis,${ }^{20}$ mesial temporal sclerosis, ${ }^{16,26}$ epidural spinal metastasis with cord compression, ${ }^{21}$ and other pathologies. Its advantages have also been translated to the management of pediatric pathologies, such as in the successful reduction of seizure burden in the treatment of pediatric epilepsy for etiologies including focal cortical dysplasia, ${ }^{3}$ mesial temporal lobe sclerosis,${ }^{14}$ and hypothalamic hamartoma, ${ }^{27}$ among others (Table 1). ${ }^{12,13}$

Kuo et al. demonstrated successful reduction in tumor volume and associated symptoms in patients with gangliogliomas, radiation necrosis, focal cortical dysplasia, and gliosis. ${ }^{13}$ Jethwa et al. reported a supratentorial primitive neuroectodermal tumor (PNET) treated with LITT in which there was resolution of neurological symptoms and no evidence of definitive recurrence at the 6-month follow-up. ${ }^{9}$ Dadey et al. reported 2 pediatric cases of sub- ependymal giant cell astrocytoma (SEGA) treated with LITT, with both patients having significant improvement in symptoms and interval decrease in lesion size at the 9-month follow-up. ${ }^{5}$ Tovar-Spinoza and Choi reported a series of 11 patients with 12 tumors including pilocytic astrocytoma, ependymoma, recurrent medulloblastoma, choroid plexus xanthogranuloma, SEGA, and ganglioglioma, in which 9 of the patients underwent LITT as initial therapy and 2 patients received it in an adjuvant fashion after other measures had failed. Postablation complications occurred in 2 patients, both of whom improved with rehabilitation with reduction of tumor volume in all instances. ${ }^{24}$ Given its minimally invasive nature, there have been few complications reported with LITT, most of which resolved in time, resulting in no permanent neurological sequelae..$^{13,24}$

Although LITT has been used in a number of pediatric intracranial pathologies as aforementioned, no currently published reports document its practicality and safety in the management of atypical teratoid/rhabdoid tumor (ATRT) as documented herein.

\section{Case Report}

A 16-month-old boy presented to medical attention with 1 week of urinary retention, constipation, and inabil- 

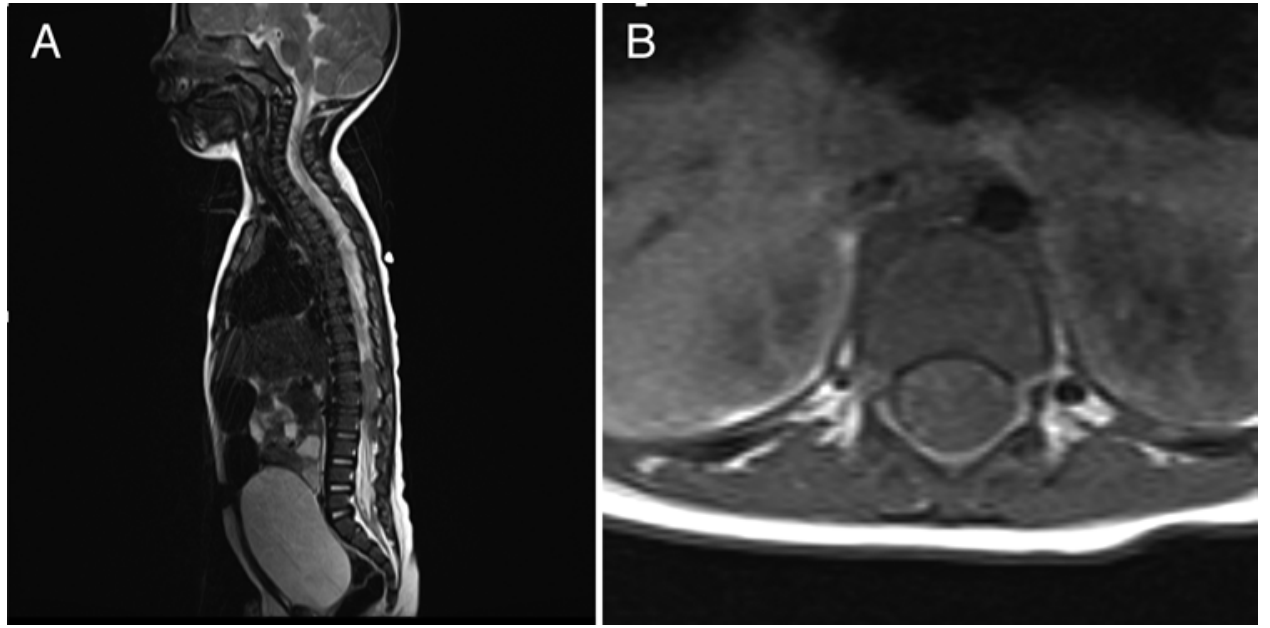

FIG. 1. Initial spine MRI obtained on presentation, with sagittal T2-weighted (A) and axial T1-weighted (B) sequences demonstrating evidence of an intramedullary mass centered over conus medullaris with dilatation of the spinal cord.

ity to walk that progressed to lower-extremity paraplegia. He underwent imaging at another hospital that revealed a large thoracolumbar mass overlying conus medullaris (Fig. 1), with separate intracranial findings of right mesial temporal and left caudate masses (Fig. 2). He was urgently transferred to our institution, where he underwent T11-L2 laminectomies for subtotal resection of an intradural intramedullary tumor. Pathology review demonstrated spinal tumor with a high mitotic index and solid sheets of uniform tumor cells with prominent nucleoli devoid of stroma and epithelial differentiation with staining suggestive of ATRT. Immunohistochemistry staining revealed the hallmark loss of nuclear INI/SMARCB1 expression. Peripher- al blood analysis provided additional supporting evidence of the diagnosis with a heterogeneous germline variant in SMARCB1 with deletions in exons 4 and 5 (Fig. 3).

Given the diagnosis, the patient was initiated on vincristine chemotherapy 2 weeks postoperatively, with a course complicated by febrile neutropenia and feeding intolerance. He subsequently underwent trials of multiple other agents including cisplatin, etoposide, and thiotepa. The patient was discharged home several weeks afterward before ultimately returning in an elective fashion for discussions regarding management of his intracranial disease with LITT, given the age-associated neurodevelopmental risks of traditional forms of irradiation and the unaccept-
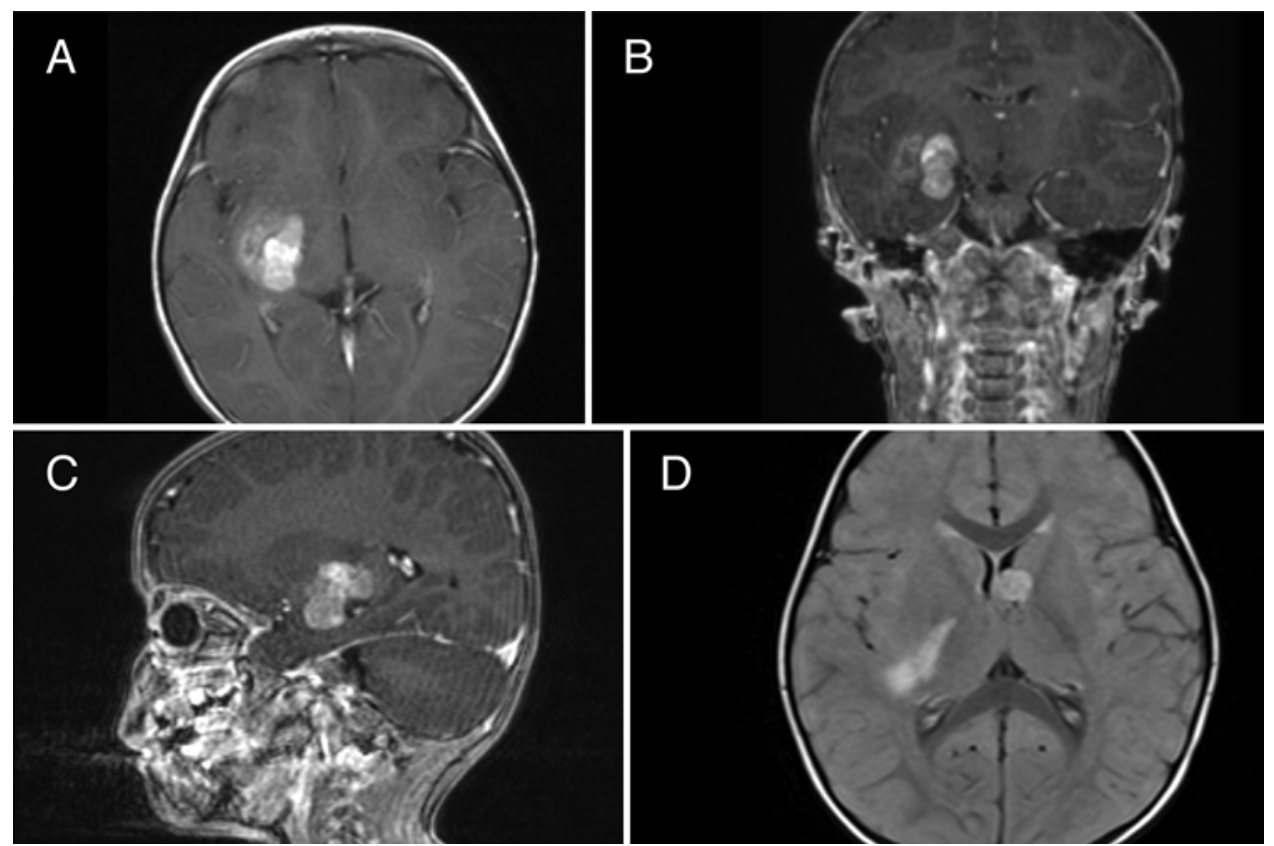

FIG. 2. Initial brain MRI obtained on presentation, with contrast-enhanced axial T1-weighted (A), coronal T1-weighted (B), and sagittal T1-weighted (C) sequences demonstrating a deep-seated lesion medial to the temporal stem. Axial T1-weighted imaging (D) also demonstrates a separate left caudate lesion. 

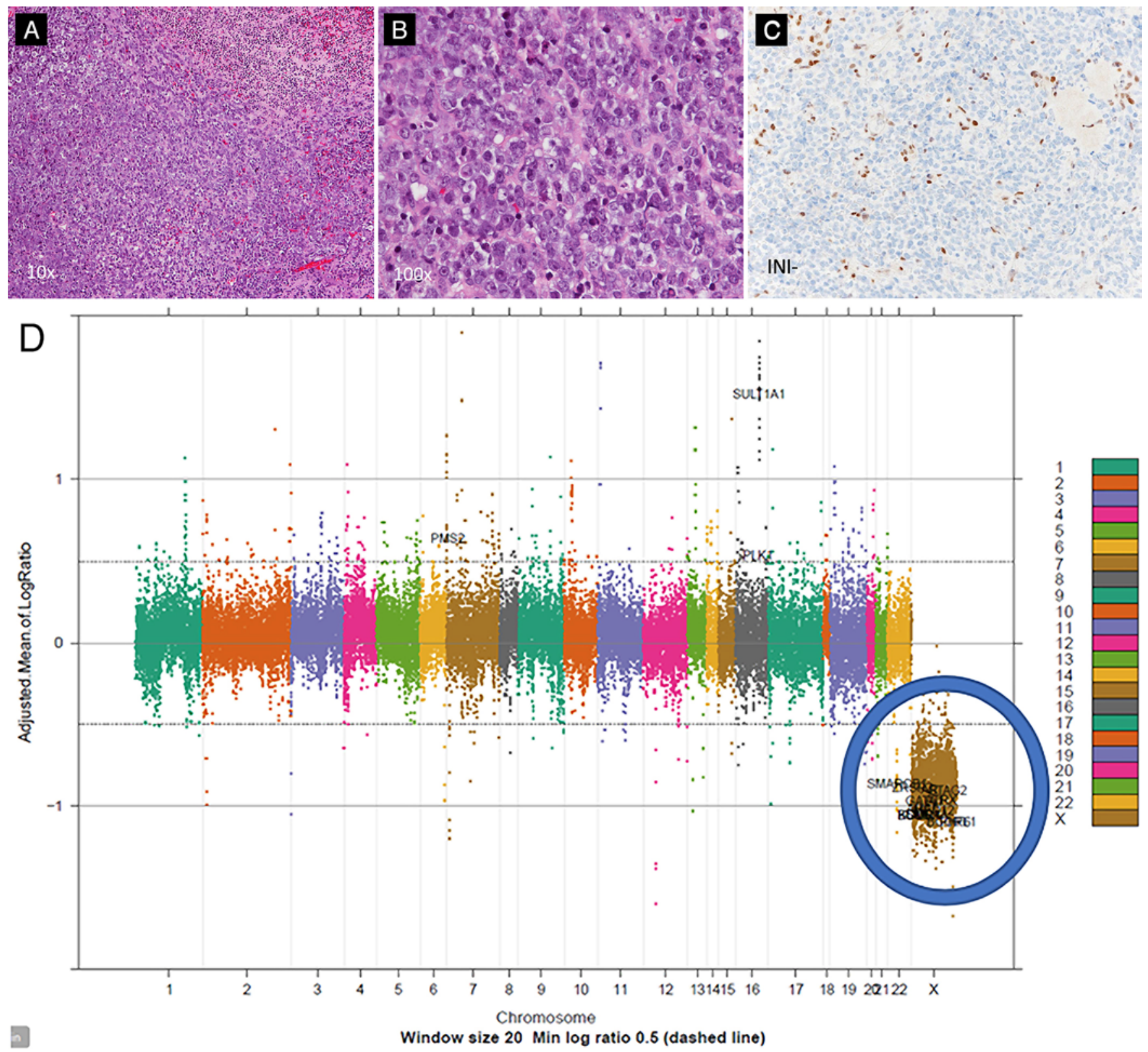

FIG. 3. Examination of histopathology demonstrates high mitotic index and solid sheets of uniform tumor cells with prominent nucleoli at low- and high-power fields ( $\mathrm{A}$ and B, H \& E stain) with negative INI1 immunohistochemical staining (C, original magnification $\times 40$ ). Sequencing of peripheral blood demonstrates characteristic SMARCB1 deletions in exons 4 and 5 (D).

ably high rate of morbidity associated with surgical extirpation of such deep-seated lesions. Similarly, he was deemed to be too ill for further chemotherapy regimens or stem cell rescue.

The patient underwent 2 stages of LITT 4 weeks apart, with targeting of the right mesial temporal and left caudate lesions, respectively. A staged approach was selected because the patient was systemically ill from his primary disease and treatment. In both instances, the laser cannula was positioned using the Medtronic Vertek arm with stereotactic guidance under sterile operative conditions. Three-tesla MRI magnets were used with contrasted T1 images to confirm appropriate placement of laser cannu- las prior to administration of test doses and final ablative trials (Fig. 4). In both instances, the patient tolerated the thermal ablation procedure without complication and was discharged home on postoperative day 1 with a 72 -hour taper of dexamethasone.

Radiographic follow-up at 2 months and 6 months after the initial LITT stage demonstrated durably treated lesions, with significant reduction in tumor burden compared with initial imaging and without any evidence of gross progression across scans (Figs. 5 and 6). Unfortunately, 3 months after the second ablation, the patient was readmitted with pulmonary failure requiring extracorporeal membrane oxygenation therapy and with Clostridium 
Feroze et al.
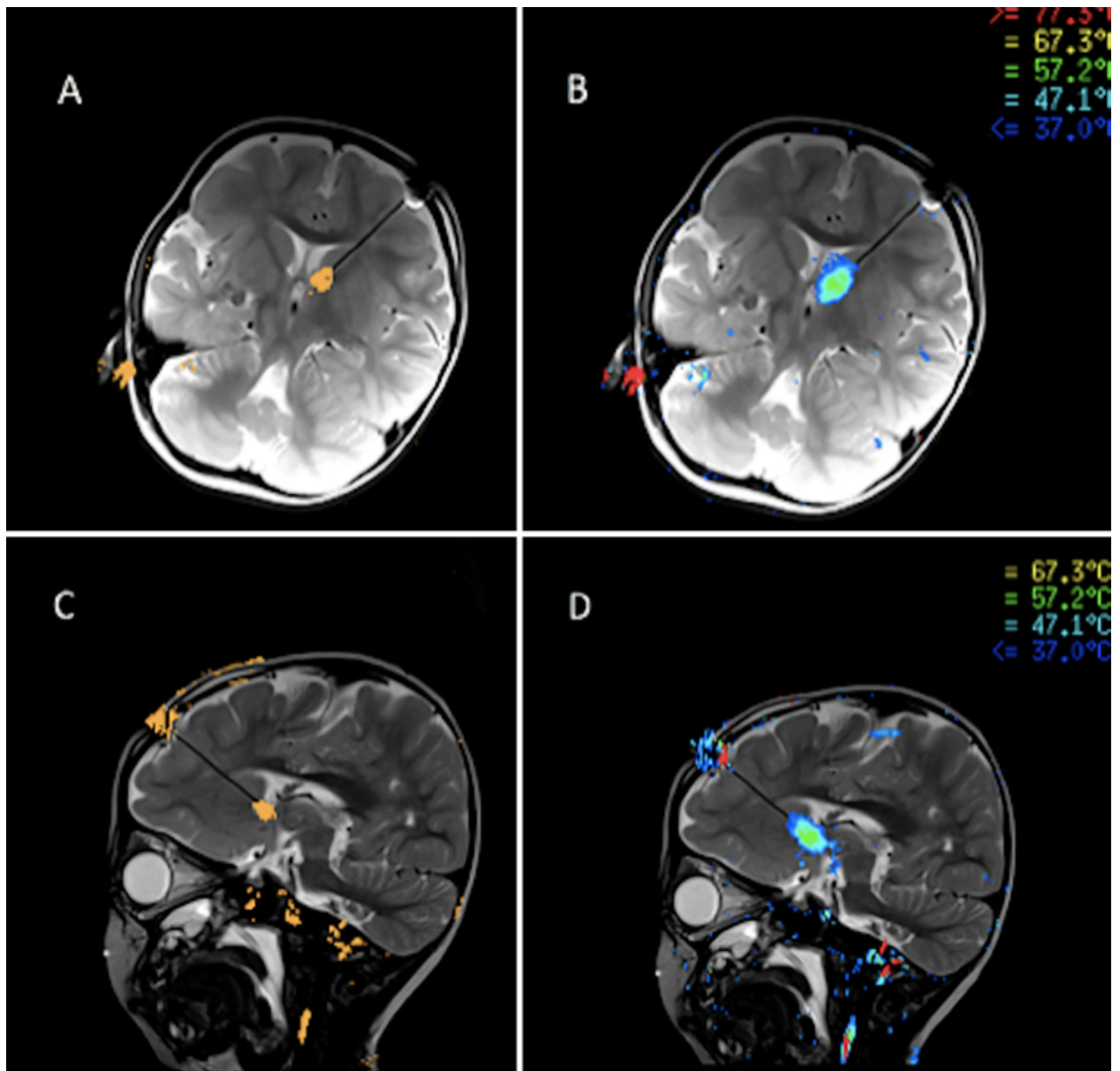

FIG. 4. Representative heat map and cannula trajectory on axial ( $A$ and $B$ ) and sagittal ( $C$ and $D)$ T2-weighted MRI sequences for ablation of left caudate lesion.
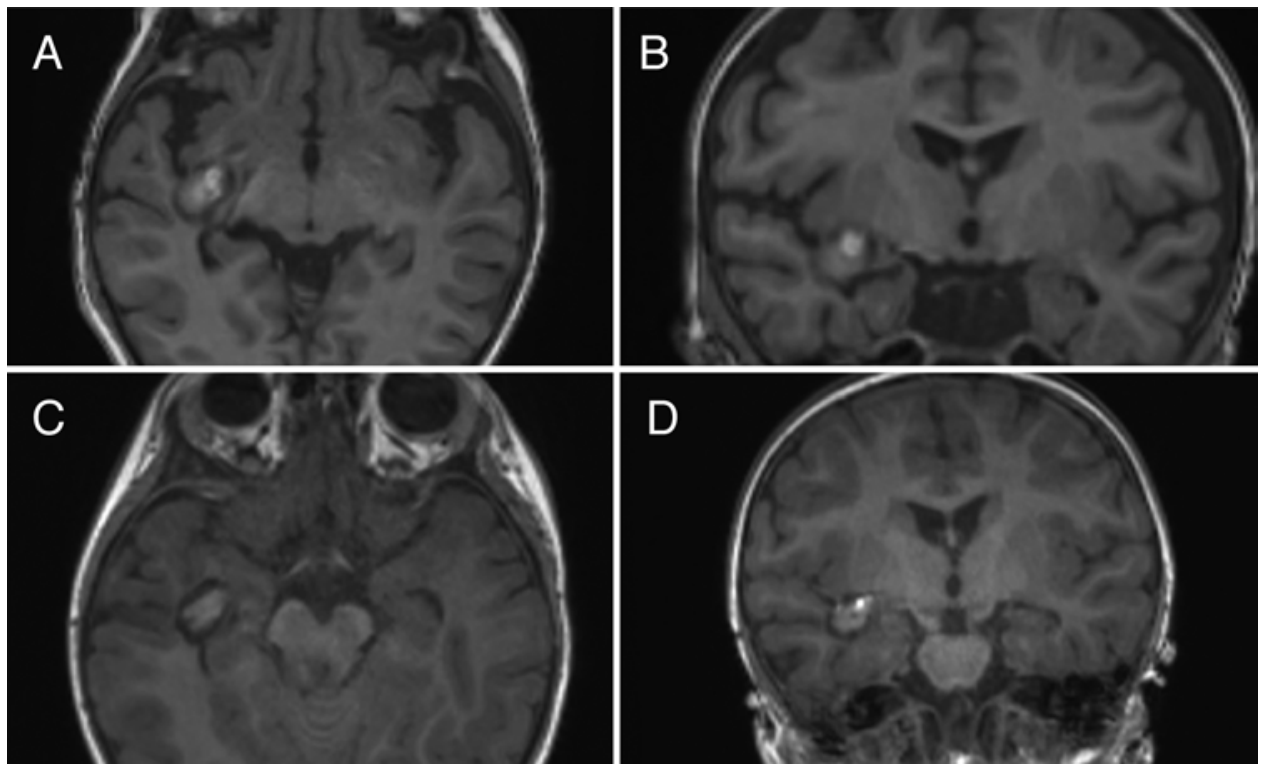

FIG. 5. Contrast-enhanced brain MRI demonstrates stability of mesial right temporal lesion on axial and coronal sequences at 2 months (A and $B$ ) and 6 months ( $C$ and $D)$ after LITT treatment. 

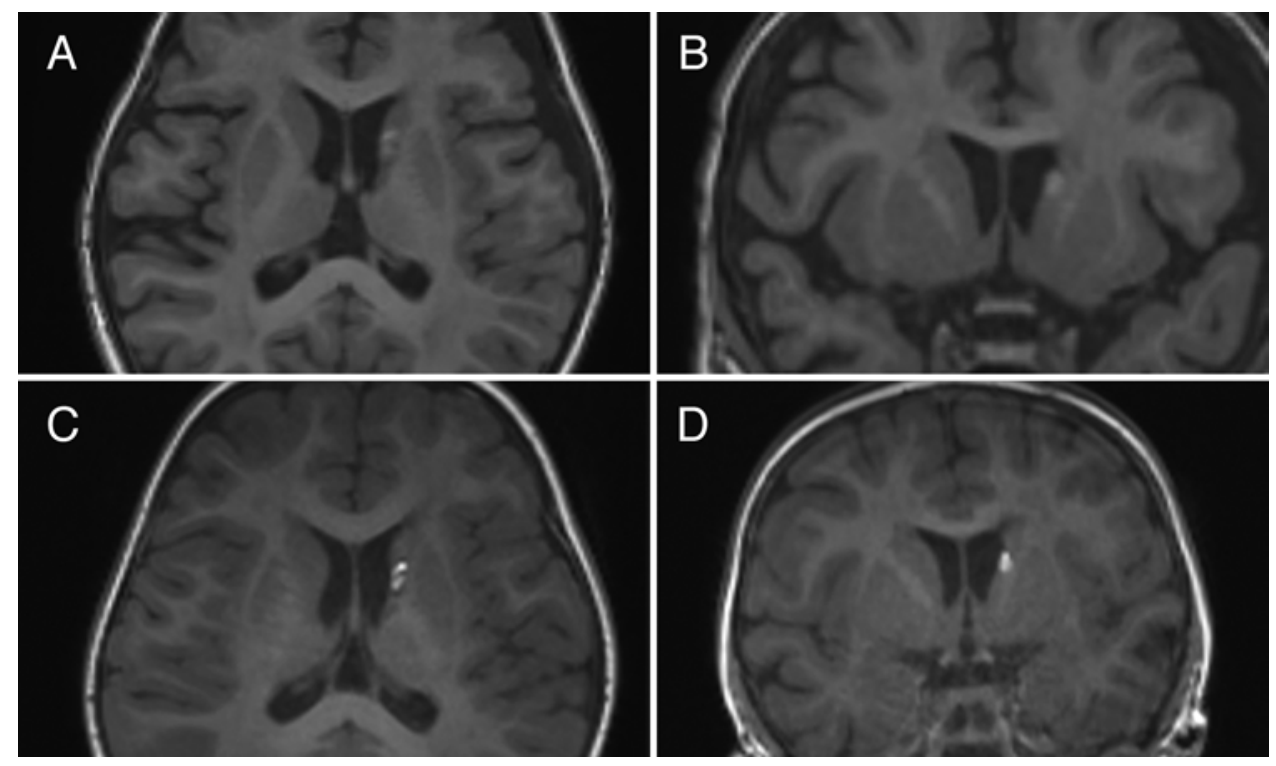

FIG. 6. Contrast-enhanced brain MRI demonstrates stability of left caudate lesion on axial and coronal sequences at 1 month (A and $\mathbf{B}$ ) and 5 months (C and $\mathbf{D})$ after LITT treatment.

tertium bacteremia. A follow-up MRI sequence obtained 6 months after his second laser ablation demonstrated marked diffuse leptomeningeal carcinomatosis, for which he was ultimately transitioned to comfort care and died shortly thereafter, 10 months after initial diagnosis and 6 months after his second intracranial LITT round.

\section{Discussion}

ATRT is a rare and aggressive embryonal tumor of the CNS. Tumors can occur anywhere in the CNS, but supratentorial tumors are more common with increasing age. ATRT accounts for approximately $4.4 \%$ of CNS neoplasms in patients younger than 5 years, with the highest incidence being in patients younger than 1 year. ${ }^{15}$ Prognoses associated with the diagnosis are poor, with 6-month, 1-year, and 5-year relative survival rates for all ages being $65.0 \%, 46.8 \%$, and $28.3 \%$, respectively. ${ }^{15}$ Inactivation of chromatin remodeling complex members by biallelic loss-of-function alterations in SMARCB1 (INI1/hSNF5) or SMARCA4 (Brg4) are diagnostic of all rhabdoid tumors. 7,25

ATRT was first described as a distinct entity in 1987, and the WHO classification of CNS tumors included ATRT for the first time in 2000. ${ }^{2}$ Diagnosis requires loss of INI1 nuclear staining, which is indicative of biallelic inactivation of SMARCB1 on chromosome $22 .{ }^{11}$ The histopathology is mixed, with some specimens entirely composed of primitive neuroectodermal components, whereas others demonstrate mesenchymal and epithelial features. Necrosis and a high rate of mitotic activity is common. Imaging typically reveals isotense or hyperintense signal with restricted diffusion that is at times difficult to reliably differentiate from pathologies such as PNETs.

There is currently no consensus regarding the standard treatment for these tumors. Reported therapeutic options include resection, multiagent chemotherapy, intrathecal chemotherapy, radiotherapy, and high-dose chemotherapy followed by autologous stem cell rescue..$^{18}$ Resection can be difficult and dangerous depending on the location of the tumors and the age of the patient. Radiation is typically avoided in young children whenever possible. There is no chemotherapy regimen that specifically targets ATRT, and the agents currently being used are chosen based on extrapolated data derived from the management of other embryonal brain tumors such as medulloblastoma.

Advances in the management and treatment of ATRT have been relatively scant, largely due to the fact that animal models of ATRT have been notoriously difficult to generate, suggesting that the tumors might arise from highly restricted cell types. Recent clinical and genomic analyses of ATRT suggest the entity to be a biologically heterogeneous disease comprising at least 2 molecular subtypes with distinct clinicopathological associations. Specifically, the category of group 1 tumors has been identified to be predominantly supratentorial, whereas group 2 tumors are found largely infratentorially. Furthermore, from a clinicopathological standpoint, Torchia et al. noted group 1 tumors to be highly enriched with genes regulating neural differentiation and proneural Notch signaling cascades (i.e., ASCL1 expression). In group 2 tumors, BMP signaling and cell migration pathways were found to be upregulated. Group 1 tumors were also implicated in a longer overall survival of approximately 29 months versus 12 months in group 2 counterparts. ${ }^{23}$ More recent evidence suggests 3 epigenetic subgroups of ATRT with distinct SMARCB1 genotypes and genomic targets including 1) group $1 / \mathrm{SHH}$ supratentorial tumors with a closed chromatin pattern and evidence of neural forebrain origin, 2) group 2A/TYR predominantly infratentorial tumors demonstrating inactivation of BMP and PDGFR $\beta$ pathways, and 3) group 2B tumors with elevated expression of $\mathrm{MYC} /$ HOX versus group $2 \mathrm{~A}$ counterparts. ${ }^{10}$ 
In children who are not candidates for radiotherapy due to neurocognitive insult and other considerations and those who demonstrate inadequate responses to chemotherapy, LITT may prove to be an effective and safe therapeutic option. Although both frame-based and frameless stereotactic approaches may be entertained, our institutional experience favors a frameless approach to allow for greater flexibility with positioning. Frame-based approaches are also reasonable but prove to be technically more challenging in young children, in whom the frame is not optimized for the infant skull. Newer frameless techniques, such as use of the ROSA robot (Medtronic), allow for the retention of the inherent benefits of frame-based approaches through the use of fiducial landmarks, and also allow for higher accuracy with targeting and shorter operating times, particularly when more than one trajectory is required. Although LITT therapy may be extended to posterior fossa lesions as well, such approaches should be used with particular caution, particularly in the setting of larger lesions, in which mass effect and hydrocephalus may make resection a safer alternative.

\section{Conclusions}

Herein, we present the first published case of pediatric ATRT treated by LITT, demonstrating its potential in the armamentarium of treatment against such a malignancy. Of note, we believe that such a modality of therapy offers treatment alternatives to surgical extirpation, which otherwise may pose significant short- and long-term neurological and neurocognitive deficits in the pediatric population. However, major limitations of our experience include those inherent to a single case report and that of limited follow-up time. Furthermore, due to the lack of next-generation sequencing performed in this instance, the specific subtype of ATRT in this patient remains unclear. As to whether LITT could prolong overall or progression-free survival in the setting of ATRT or whether it may play a role in either the adjuvant or neoadjuvant setting remains to be evaluated. Nevertheless, with low rates of associated morbidity and minimal coupled with limited postoperative inpatient stays and the use of nonionizing radiation in the pediatric setting, LITT offers an attractive alternative option in the management of pediatric ATRT that is deserving of further investigation.

\section{References}

1. Ashraf O, Patel NV, Hanft S, Danish SF: Laser-induced thermal therapy in neuro-oncology: a review. World Neurosurg 112:166-177, 2018

2. Biggs PJ, Garen PD, Powers JM, Garvin AJ: Malignant rhabdoid tumor of the central nervous system. Hum Pathol 18:332-337, 1987

3. Buckley RT, Wang AC, Miller JW, Novotny EJ, Ojemann JG: Stereotactic laser ablation for hypothalamic and deep intraventricular lesions. Neurosurg Focus 41(4):E10, 2016

4. Curry DJ, Gowda A, McNichols RJ, Wilfong AA: MR-guided stereotactic laser ablation of epileptogenic foci in children. Epilepsy Behav 24:408-414, 2012

5. Dadey DY, Kamath AA, Leuthardt EC, Smyth MD: Laser interstitial thermal therapy for subependymal giant cell astrocytoma: technical case report. Neurosurg Focus 41(4):E9, 2016
6. Fayed I, Sacino MF, Gaillard WD, Keating RF, Oluigbo CO: MR-guided laser interstitial thermal therapy for medically refractory lesional epilepsy in pediatric patients: experience and outcomes. Pediatr Neurosurg 53:322-329, 2018

7. Hasselblatt M, Gesk S, Oyen F, Rossi S, Viscardi E, Giangaspero F, et al: Nonsense mutation and inactivation of SMARCA4 (BRG1) in an atypical teratoid/rhabdoid tumor showing retained SMARCB1 (INI1) expression. Am J Surg Pathol 35:933-935, 2011

8. Hoppe C, Witt JA, Helmstaedter C, Gasser T, Vatter H, Elger CE: Laser interstitial thermotherapy (LiTT) in epilepsy surgery. Seizure 48:45-52, 2017

9. Jethwa PR, Lee JH, Assina R, Keller IA, Danish SF: Treatment of a supratentorial primitive neuroectodermal tumor using magnetic resonance-guided laser-induced thermal therapy. J Neurosurg Pediatr 8:468-475, 2011

10. Johann PD, Erkek S, Zapatka M, Kerl K, Buchhalter I, Hovestadt V, et al: Atypical teratoid/rhabdoid tumors are comprised of three epigenetic subgroups with distinct enhancer landscapes. Cancer Cell 29:379-393, 2016

11. Judkins AR, Mauger J, Ht A, Rorke LB, Biegel JA: Immunohistochemical analysis of hSNF5/INI1 in pediatric CNS neoplasms. Am J Surg Pathol 28:644-650, 2004

12. Karsy M, Patel DM, Halvorson K, Mortimer V, Bollo RJ: Anterior two-thirds corpus callosotomy via stereotactic laser ablation. Neurosurg Focus 44 (VideoSuppl2):V2, 2018

13. Kuo CH, Feroze AH, Poliachik SL, Hauptman JS, Novotny EJ Jr, Ojemann JG: Laser ablation therapy for pediatric patients with intracranial lesions in eloquent areas. World Neurosurg 121:e191-e199, 2019

14. Lewis EC, Weil AG, Duchowny M, Bhatia S, Ragheb J, Miller I: MR-guided laser interstitial thermal therapy for pediatric drug-resistant lesional epilepsy. Epilepsia 56:1590-1598, 2015

15. Ostrom QT, Chen Y, de Blank PM, Ondracek A, Farah P, Gittleman H, et al: The descriptive epidemiology of atypical teratoid/rhabdoid tumors in the United States, 2001-2010. Neuro Oncol 16:1392-1399, 2014

16. Prince E, Hakimian S, Ko AL, Ojemann JG, Kim MS, Miller JW: Laser interstitial thermal therapy for epilepsy. Curr Neurol Neurosci Rep 17:63, 2017

17. Rodriguez A, Tatter SB: Laser ablation of recurrent malignant gliomas: current status and future perspective. Neurosurgery 79 (Suppl 1):S35-S39, 2016

18. Schrey D, Carceller Lechón F, Malietzis G, Moreno L, Dufour C, Chi S, et al: Multimodal therapy in children and adolescents with newly diagnosed atypical teratoid rhabdoid tumor: individual pooled data analysis and review of the literature. J Neurooncol 126:81-90, 2016

19. Schwarzmaier HJ, Eickmeyer F, Fiedler VU, Ulrich F: Basic principles of laser induced interstitial thermotherapy in brain tumors. Med Laser Appl 17:147-158, 2002

20. Smith CJ, Myers CS, Chapple KM, Smith KA: Long-term follow-up of 25 cases of biopsy-proven radiation necrosis or post-radiation treatment effect treated with magnetic resonance-guided laser interstitial thermal therapy. Neurosurgery 79 (Suppl 1):S59-S72, 2016

21. Tatsui CE, Lee SH, Amini B, Rao G, Suki D, Oro M, et al: Spinal laser interstitial thermal therapy: a novel alternative to surgery for metastatic epidural spinal cord compression. Neurosurgery 79 (Suppl 1):S73-S82, 2016

22. Thomas JG, Rao G, Kew Y, Prabhu SS: Laser interstitial thermal therapy for newly diagnosed and recurrent glioblastoma. Neurosurg Focus 41(4):E12, 2016

23. Torchia J, Picard D, Lafay-Cousin L, Hawkins CE, Kim SK, Letourneau L, et al: Molecular subgroups of atypical teratoid rhabdoid tumours in children: an integrated genomic and clinicopathological analysis. Lancet Oncol 16:569-582, 2015

24. Tovar-Spinoza Z, Choi H: Magnetic resonance-guided laser 
interstitial thermal therapy: report of a series of pediatric brain tumors. J Neurosurg Pediatr 17:723-733, 2016

25. Versteege I, Sévenet N, Lange J, Rousseau-Merck MF, Ambros P, Handgretinger R, et al: Truncating mutations of hSNF5/INI1 in aggressive paediatric cancer. Nature 394:203-206, 1998

26. Wicks RT, Jermakowicz WJ, Jagid JR, Couture DE, Willie JT, Laxton AW, et al: Laser interstitial thermal therapy for mesial temporal lobe epilepsy. Neurosurgery 79 (Suppl 1):S83-S91, 2016

27. Xu DS, Chen T, Hlubek RJ, Bristol RE, Smith KA, Ponce FA, et al: Magnetic resonance imaging-guided laser interstitial thermal therapy for the treatment of hypothalamic hamartomas: a retrospective review. Neurosurgery 83:1183-1192, 2018

\section{Disclosures}

Dr. Hauptman is a consultant for Medtronic.

\section{Author Contributions}

Conception and design: Feroze, Hauptman. Acquisition of data: Feroze, McGrath, Cole, Hauptman. Analysis and interpretation of data: Feroze, McGrath, Williams, Young, Ene. Drafting the article: Feroze, McGrath, Williams, Young. Critically revising the article: Feroze, McGrath, Williams, Young, Buckley, Ojemann, Hauptman. Reviewed submitted version of manuscript: Feroze, McGrath, Williams, Ene, Buckley, Ojemann, Hauptman. Approved the final version of the manuscript on behalf of all authors: Feroze. Study supervision: Ojemann, Hauptman.

\section{Correspondence}

Abdullah H. Feroze: University of Washington, Seattle, WA. aferoze@uw.edu. 